\title{
WHY INTERNATIONAL EQUITY INFLOWS TO EMERGING MARKETS ARE INEFFICIENT AND SMALL RELATIVE TO INTERNATIONAL DEBT INFLOWS
}

\author{
Assaf Razin \\ Efraim Sadka \\ Chi-Wa Yuen \\ Working Paper 8659 \\ http://www.nber.org/papers/w8659 \\ NATIONAL BUREAU OF ECONOMIC RESEARCH \\ 1050 Massachusetts Avenue \\ Cambridge, MA 02138 \\ December 2001
}

Research on this paper was conducted while the authors were visiting the International Monetary Fund, Razin and Yuen at the Research Department and Sadka at the Fiscal Affairs Department. We thank Lunar Cheng, Keith Wong, Edgardo Zablotsky, and seminar participants at CEMA for useful discussion. The usual disclaimer applies. The views expressed herein are those of the authors and not necessarily those of the National Bureau of Economic Research, HRDC or Statistics Canada.

(C) 2001 by Assaf Razin, Efraim Sadka and Chi-Wa Yuen. All rights reserved. Short sections of text, not to exceed two paragraphs, may be quoted without explicit permission provided that full credit, including $(C$ notice, is given to the source. 
Why International Equity Inflows to Emerging Markets are Inefficient and Small Relative to International Debt Inflows Assaf Razin, Efraim Sadka and Chi-Wa Yuen

NBER Working Paper No. 8659

December 2001

JEL No. F21, F35, H25, H30

\begin{abstract}
This paper considers the financing of investment in the presence of asymmetric information between the "insiders" and the "outsiders" of the firms in a small open economy. It establishes a welldefined capital structure for the economy as a whole with the following features: low-productivity firms rely on the equity market to finance investment at a relatively low level; medium-productivity firms do not invest at all; and high-productivity firms rely on the debt market to finance investment at a relatively high level. It is shown that the debt market is efficient, with respect to both its scope and the amount of investment that each firm makes. However, the equity market fails: its scope is too narrow and the investment each firm makes is too little. A corrective policy requires just one instrument which is rather unconventional: lump-sum subsidies to those firms that choose to equity-finance their investment (i.e., equity-market-contingent grants).
\end{abstract}

\author{
Assaf Razin \\ Eitan Berglas School of Economics \\ Tel Aviv University \\ Tel Aviv 69978 \\ Israel \\ and NBER \\ razin@econ.tau.ac.il \\ Chi-Wa Yuen \\ School of Economics and Finance \\ University of Hong Kong \\ Pokfulam Road \\ Hong Kong \\ cwyuen@econ.hku.hk
}

Efraim Sadka

Eitan Berglas School of Economics

Tel Aviv University

Tel Aviv 69978

Israel

sadka@econ.tau.ac.il 


\section{Introduction}

Learned observations about less developed countries indicate that their capital markets are immature and commonly plagued by informational and other problems such as absence of international disclosure standards and regulatory forbearance in recognizing the extent of bad loans. As the economies develop over time, these problems can be mitigated in one way or another but they are still very much in presence to drive noticeable differences among the various means of investment financing. Indeed, Figure 1 reveals that although the major three types of net private capital flows into developing countries) | viz., foreign direct investment (FDI), portfolio equity flows, and debt flows/|co-move and are trending upward, their magnitudes differ substantially: FDI and debt flows occupy a more prominent position than equity flows. While debt and equity flows are mainly a source of finance for investment in the capital-importing countries, FDI has other distinguishable attributes: as a means of bypassing trade barriers and of technology transfer, a way for multinationals to be close to local consumer markets, etc. In this paper, we shall abstract from the analysis of FDI and focus only on the differences between the two types of portfolio capital flows. ${ }^{1}$

\section{[insert Figure 1 about here]}

In a perfect capital market, all forms of capital financing are indistinguishable and there is no unique debt-equity structure within a firm or in the economy as a whole. Similarly, there is no meaningful economic difference between international debt and equity flows. In the presence of information asymmetry between the firm's "insiders" and "outsiders", however, we can derive a well-defined debt-equity capital structure for the whole economy. Under asymmetric information, the equity market may be plagued by a "lemons" problem while the debt market by

${ }^{1}$ For an analysis of one important aspect of FDI) / viz., as direct control over domestic investment projects, which facilitates acquisition of insider information about the productivity of the firms) | see Razin, Sadka, and Yuen (1998a). 
possibilities of default. In such context, we can endogenously determine the co-existence of three groups of firms: firms which equity-finance new investment, firms which debt-finance new investment, and firms which make no new investment. This economy-wide debt-equity structure also induces a similar pattern for the two major channels of international finance, i.e., debt and equity flows.

Under this equilibrium capital structure of the economy, two kinds of efficiency issues arise. One can ask (1) if the firm's decision of whether to make new investment or not to invest at all is efficient; and (2) if those firms that choose to make new investment will invest inadequately or excessively. In order to address these issues, we develop a concept of constrained Pareto-efficiency that takes into account the limitations imposed on the manager in carrying out the investment plans of the firm in the asymmetric information environment. Given the uncommon nature of this efficiency problem, the corrective policy may also assume an unconventional structure.

Similar to the aforementioned order of capital flows, there is a pecking order in corporate finance. In financing new investment projects, the manager, who is better informed than the suppliers of funds, would prefer to rely on retained earnings (the counterpart of FDI). If these funds are insufficient, debt is preferred to equity since the choice of equity finance sends the potential signal that the manager thinks the firm's shares are overvalued (see Myers and Majluf, 1984). However, our analysis of debt and equity finance differs from that in the corporate finance literature. While the latter is based on analysis of a single firm's investment and financing decisions focusing on issues of corporate governance, we abstract from the governance issues in order to focus on the macro-economic and international finance issues. We thus consider both the demand for funds (i.e., the investment and financing decisions of the firms) and the supply of funds (i.e., the saving decisions of the consumers) in a general equilibrium framework. In 
particular, we are interested in the efficiency implications of the various means of finance and the scope for corrective policy.

The organization of the paper is as follows. Section II describes the analytical framework) | classifying firms into three categories (i.e., those with equity-financed investment, debt-financed investment, and no new investment), deriving the firm's optimal investment rule, and laying out the equilibrium conditions in the economy. Section III introduces a concept of constrained efficiency for evaluation of the market equilibrium. Section IV compares the market conditions with the efficiency conditions, explains the nature of market failure in this context, and proposes an optimal corrective policy. Concluding remarks are provided in Section V.

\section{Analytical Framework}

Suppose there is a very large number $(\mathrm{N})$ of ex ante identical domestic firms. Each firm employs capital input $(\mathrm{K})$ in the first period in order to produce a single composite good in the second period. We assume that capital depreciates at the rate ä $(<1)$. Output in the second period is equal to $\mathrm{F}(\mathrm{K})(1+\varepsilon)$, where $\mathrm{F}($.) is a production function exhibiting diminishing marginal productivity of capital and $\varepsilon$ is a random productivity factor. The latter has zero mean and is independent across all firms. ( $\varepsilon$ is bounded between -1 and 1 , so that output is always nonnegative.) We assume that $\varepsilon$ is purely idiosyncratic, so that there is no aggregate uncertainty. ${ }^{2}$,

${ }^{3}$ Consumer-investors will thus behave in a risk-neutral way.

\footnotetext{
${ }^{2}$ This assumption may differ from what is assumed in some strands of the corporate finance literature whereby return volatilities may vary across firms. If firms are different by their ex ante risk characteristics, then higher-volatility firms would face higher ex ante default risk if they issue debt. As a result, their gearing (i.e., debt-equity) ratio will be lower than the low-volatility firms. Since a high-risk firm must offer its shareholders higher expected return, there must be a negative cross-sectional correlation between mean return and the gearing ratio. We abstract, however, from this variable volatility assumption, and assume instead identical ex ante risk characteristics, in order to focus on an alternative mechanism that links firm productivities with their debt-equity ratios.
}

\footnotetext{
${ }^{3}$ In our small open economy context, there may exist another kind of risk due to the difference in the currency denominations of debt and equity: while dividend payments on equity are normally denominated in terms of
} 
In the first period, firms determine their investment rules in the planning stage while the actual investment and its funding are delayed to the implementation stage. These investment rules are approved by the owners of the firms before realization of their productivity shocks. The management then implements these rules by seeking funds, either at home or abroad, to finance the investment after $\varepsilon$ is known. For simplicity, we assume that the original owners of the investment sites do not have any retained earnings to finance their capital outlays, and will have to appeal to the equity or debt market instead. At the implementation and financing stage, the managers of the firms are better informed than the outside fund-suppliers (both foreign and domestic). There are many ways to specify the degree of this asymmetry in information. In order to facilitate the analysis, however, we simply assume that the managers, being "close to the action", observe $\varepsilon$ before they implement the investment rules and make their financing decisions; but the fund-providers, being "far away from the action", do not. ${ }^{4}$

A possible rationale behind this sequence of firm decisions whereby the investment choice is made ex ante while the financing of the pre-committed investment is decided ex post has to do with a potential agency problem between the board of directors (representing the owners) and the managers (who are responsible for making these decisions). Loosely speaking, the latter are less interested in the net worth of the firm than the former. In the absence of full information about the firm's productivity, the owners will have to set investment guidelines for the managers so as

domestic currency, interest payments on debt may be denominated in terms of foreign currency. So the existence of exchange rate risk may introduce a non-trivial difference between equity and debt in the international context. But this kind of risk is symmetric to both insiders and outsiders of firms. We shall abstract from modelling it in our asymmetric information framework.

\footnotetext{
${ }^{4}$ The information about $\varepsilon$ here is asymmetric between the firms (domestic investors) on the one hand and the suppliers of funds (domestic and foreign savers) on the other, in contrast to the asymmetric information structure between domestic savers on the one hand and foreign savers on the other as developed by Gordon and Bovenberg (1996) and extended by Razin, Sadka, and Yuen (1998b). The latter type of information asymmetry gives rise to home-biased portfolio investment as documented by Tesar and Werner (1995). Many of the structural features of the Gordon-Bovenberg model are retained in this paper.
} 
to protect their own interests. This agency problem is not modelled explicitly here because we want to focus instead on the asymmetric information between the firm's "insiders" and "outsiders". What we do capture in our model is the spirit of these investment guidelines in terms of the sequencing of information and the firm's investment and financing decisions.

The investment rules are, however, quite rigid in the degrees of freedom they allow the management. Depending on the realized value of the productivity factor $(\varepsilon)$, it may be strikingly more advantageous to debt-finance or equity-finance new investment or not to invest at all. For instance, a higher-than-average value of $\varepsilon$ which is observed by the manager but not by the fundsuppliers will be insufficiently priced by the equity market. In such a case, it will not be optimal for the manager to resort to the equity market. Similarly, a low realization of $\varepsilon$ observed by the manager but not by potential creditors will make it unprofitable for the manager to issue debt even though she is able to do so (as the creditors do not observe $\varepsilon$ ) because of the detrimental effects of default. In the case of default, the original owner loses part or all of the existing capital; whereas if the firm takes no loans and makes no new investment, she can retain all of the existing capital.

Specifically, the investment rule dictates the manager to take either one of three possible courses of actions once $\varepsilon$ is made known to her:

(i) equity-finance new capital investment, so as to augment the stock of capital of the firm to a pre-determined level of $\mathrm{K}^{-}$;

(ii) debt-finance new capital investment, so as to augment the stock of capital of the firm to a pre-determined level of $\mathrm{K}^{+}$; and

(iii) not to invest at all.

Since all firms face the same probability distribution of $\varepsilon$ when designing their investment rules, they all choose the same rule (i.e., the same $\mathrm{K}^{-}$and $\mathrm{K}^{+}$). 


\section{II.A Which firms will equity-finance investment?}

As mentioned above, the managers observe $\varepsilon$ while the new potential shareholders of the firm do not. The market will be trapped in the "lemons" situation a la Akerlof (1970). At the price offered by the new (uninformed) potential equity buyers, which reflects the average productivity of all firms (i.e., the average level of $\varepsilon$ ) in the market, the manager of a firm experiencing a higher-than-average value of $\varepsilon$ would prefer to employ just the existing capital (i.e., $\mathrm{K}_{0}$ ) rather than to raise equity from a market that will not pay a premium for a high value of $\varepsilon$. Thus, there exists a cutoff level of $\varepsilon$, denoted by $\varepsilon_{0}$, such that all firms which experience a value of $\varepsilon$ above $\varepsilon_{0}$ will not make any new investment while all other firms (i.e., the low- $\varepsilon$ firms) will equity-finance their new investment at a price reflecting the average value of the "lemons". Define $\mathrm{e}^{-}$as the mean value of $\varepsilon$ realized by the low productivity firms:

$$
e^{-} \equiv E\left(\varepsilon / \varepsilon \leq \varepsilon_{0}\right)=\int_{-1}^{\varepsilon_{0}} \varepsilon\left[\ddot{O}^{\prime}(\varepsilon) / O ̈\left(\varepsilon_{0}\right)\right] d \varepsilon,
$$

where $\ddot{O}($.$) is the cumulative probability distribution of \varepsilon$. That is, $\mathrm{e}^{-}$is the conditional expectation of $\varepsilon$, given that $\varepsilon \leq \varepsilon^{0}$.

The cutoff level of $\varepsilon$ is then defined by

$$
\begin{gathered}
-\left[\mathrm{K}^{-}-(1-\ddot{\mathrm{a}}) \mathrm{K}_{0}\right]+\left\{\mathrm{F}\left(\mathrm{K}^{-}\right)\left[1+\mathrm{e}^{-}\left(\varepsilon_{0}\right)\right]+(1-\ddot{\mathrm{a}}) \mathrm{K}^{-}\right\} /\left(1+\mathrm{r}^{*}\right) \\
=\left\{\mathrm{F}\left[(1-\ddot{\mathrm{a}}) \mathrm{K}_{0}\right]\left(1+\varepsilon_{0}\right)+(1-\ddot{\mathrm{a}})^{2} \mathrm{~K}_{0}\right\} /\left(1+\mathrm{r}^{*}\right),
\end{gathered}
$$

where $\mathrm{K}^{-}$is the stock of capital of the low- $\varepsilon$ firms that do make new investment, $(1-\ddot{a}) \mathrm{K}_{0}$ the undepreciated initial stock of capital for the firms that do not make any new investment, and $\mathrm{r}^{*}$ the world rate of interest.

We assume a small open economy so that the domestic rate of interest is determined exogenously by the world rate $\left(\mathrm{r}^{*}\right)$. The left-hand side of equation (2) represents the market value 
of the firm net of the new capital investment. Note that, to the potential new shareholders, all firms on the market are indistinguishable so that their productivity is evaluated at $\mathrm{e}^{-}$, i.e., the average productivity of the group of firms that choose to equity-finance their new investment. The right-hand side of (2) represents the value of the marginal firm to the manager who observes $\varepsilon$ and acts on behalf of the original firm owner. By the marginal firm, we mean the firm with the lowest productivity factor $\left(\varepsilon_{0}\right)$ among the firms that do not make equity-financed new investment.

\section{II.B Which firms will debt-finance investment?}

Besides equity finance, an alternative source of finance is to have domestic firms borrow from banks or float bonds. ${ }^{5}$ As in Stiglitz and Weiss (1981), we allow for the possibility of default. However, since the manager observes the realized value of $\varepsilon$ before proceeding with the actual implementation of the pre-determined level of investment (denoted by $\left.\mathrm{K}^{+}-(1-\ddot{\mathrm{a}}) \mathrm{K}_{0}\right)$ and the borrowing needed for its finance, it will never pay her to borrow if she knows that the firm will not be able to repay its loans at the end (i.e., it does not pay to default). This is because in the latter case, all its post-investment assets (i.e., $\left.\mathrm{F}\left(\mathrm{K}^{+}\right)(1+\varepsilon)+(1-\ddot{a}) \mathrm{K}^{+}\right)$will be seized, leaving the firm pennyless; while if it decides not to borrow to finance new investment, then it will still be left with $\mathrm{F}\left[(1-\ddot{\mathrm{a}}) \mathrm{K}_{0}\right]+(1-\ddot{\mathrm{a}})^{2} \mathrm{~K}_{0}{ }^{6}$

Therefore, there will be a cutoff level of $\varepsilon$, denoted by $\varepsilon^{0}$, such that all firms that realize a value of $\varepsilon$ below $\varepsilon^{0}$ will not make any new investment and all other firms will borrow $\mathrm{K}^{+}-(1-\ddot{\mathrm{a}}) \mathrm{K}_{0}$ in order to increase their capital stock to $\mathrm{K}^{+}$. This cutoff level of $\varepsilon$ is given by

$$
-\left[\mathrm{K}^{+}-(1-\ddot{\mathrm{a}}) \mathrm{K}_{0}\right]+\left[\mathrm{F}\left(\mathrm{K}^{+}\right)\left(1+\varepsilon^{0}\right)+(1-\ddot{\mathrm{a}}) \mathrm{K}^{+}\right] /\left(1+\mathrm{r}^{*}\right)
$$

\footnotetext{
${ }^{5}$ A related issue of sovereign debt in the context of asymmetric information is discussed in Eaton and Gersovitz (1989).

${ }^{6}$ With moral hazard, the possibility of default becomes more real. See, e.g., Gertler and Rogoff (1990) and Lane (1998).
} 


$$
=\left\{\mathrm{F}\left[(1-\ddot{\mathrm{a}}) \mathrm{K}_{0}\right]\left(1+\varepsilon^{0}\right)+(1-\ddot{\mathrm{a}})^{2} \mathrm{~K}_{0}\right\} /\left(1+\mathrm{r}^{*}\right),
$$

The left-hand side of (3) represents the market value, net of the new investment, of the marginal firm that debt-finances new investment; while the right-hand side represents the alternative market value for that firm if it chooses not to invest. By the marginal firm, we mean here the firm with the lowest realized productivity value among the group of firms that make debt-financed investment.

For later use, we denote the mean value of the productivity factor for the firms that debtfinance their investment by $\mathrm{e}^{+}$, i.e.,

$$
e^{+} \equiv E\left(\varepsilon / \varepsilon \geq \varepsilon^{0}\right)=\int_{\varepsilon}^{1} \varepsilon\left\{\ddot{O}^{\prime}(\varepsilon) /\left[1-\ddot{\mathrm{O}}\left(\varepsilon^{0}\right)\right]\right\} d \varepsilon
$$

In other words, $\mathrm{e}^{+}$is the conditional expectation of $\varepsilon$, given $\varepsilon \geq \varepsilon_{0}$.

\section{II.C Which firms do not make new investment?}

All the firms that realize a value of $\varepsilon$ above $\varepsilon_{0}$ and below $\varepsilon^{0}$ will neither equity-finance nor debt-finance such investment, i.e., they will not invest at all. This set of firms is not empty when $\varepsilon_{0}<\varepsilon^{0}$. By comparing conditions (2) and (3), one can see that $\varepsilon_{0}$ is indeed below $\varepsilon^{0}$. Suppose not, then the right-hand side of (2) will either equal or exceed the right-hand side of (3). It follows that the left-hand side of (2) will also equal or exceed the left-hand side of (3). But this is impossible because the left-hand side of (2) represents the mean market value of the low- $\varepsilon$ firms while the left-hand side of (3) represents the market value of the marginal high- $\varepsilon$ firm.

For later use, we define by $\mathrm{e}^{0}$ the mean value of $\varepsilon$ for the firms that make no new investment, i.e., 


$$
e^{0} \equiv E\left(\varepsilon / \varepsilon_{0} \leq \varepsilon \leq \varepsilon^{0}\right)=\int_{\varepsilon_{0}}^{\varepsilon^{0}}\left\{\varepsilon \ddot{\mathrm{O}}^{\prime}(\varepsilon) /\left[\ddot{\mathrm{O}}\left(\varepsilon^{0}\right)-\ddot{\mathrm{O}}\left(\varepsilon_{0}\right)\right]\right\} d \varepsilon
$$

In other words, $\mathrm{e}^{0}$ is the conditional expectation of $\varepsilon$, given $\varepsilon_{0} \leq \varepsilon \leq \varepsilon^{0}$.

\section{II.D The capital structure of the economy}

In this economy, the set of firms is divided into three groups:

(1) There are NÖ $\left(\varepsilon_{0}\right)$ low- $\varepsilon$ firms (i.e., firms with realized values of $\varepsilon$ below $\varepsilon_{0}$ ) which equityfinance their new investment that augments the capital stock of each one of them to $\mathrm{K}^{-}$.

(2) There are $\mathrm{N}\left[\ddot{\mathrm{O}}\left(\varepsilon^{0}\right)-\mathrm{O}\left(\varepsilon_{0}\right)\right]$ medium- $\varepsilon$ firms (i.e., firms with realized values of $\varepsilon$ between $\varepsilon_{0}$ and $\varepsilon^{0}$ ) that make no new investment and operate with the undepreciated initial stock of capital $(1-\ddot{a}) \mathrm{K}_{0}$.

(3) There are $\mathrm{N}\left[1-\mathrm{O}\left(\varepsilon^{0}\right)\right]$ high- $\varepsilon$ firms (i.e., firms with realized values of $\varepsilon$ above $\varepsilon^{0}$ ) which debt-finance new investment that augments the capital stock of each one of them to $\mathrm{K}^{+}$.

\section{II.E The investment rule}

The initial owner-managers determine $\mathrm{K}^{-}$and $\mathrm{K}^{+}$in the first stage before the realization of $\varepsilon$. They nonetheless take into account the second-stage implementation procedure that gives the managers the option of not investing at all once the managers observe $\varepsilon$.

The objective of the owner-managers is to maximize the expected market value of the firm, which is given by 


$$
\begin{array}{r}
E\left[V\left(K_{0}\right)\right]=\ddot{\mathrm{O}}\left(\varepsilon_{0}\right)\left\{\left[\frac{F\left(K^{-}\right)\left(1+e^{-}\right)+(1-\ddot{\mathrm{a}}) K^{-}}{1+r^{*}}\right]-\left[K^{-}-(1-\ddot{\mathrm{a}}) K_{0}\right]\right\} \\
+\left[\ddot{\mathrm{O}}\left(\varepsilon^{0}\right)-\ddot{\mathrm{O}}\left(\varepsilon_{0}\right)\right]\left\{\frac{F\left[(1-\ddot{\mathrm{a}}) K_{0}\right]\left(1+e^{0}\right)+(1-\ddot{\mathrm{a}})^{2} K_{0}}{1+r^{*}}\right\} \\
+\left[1-\ddot{\mathrm{O}}\left(\varepsilon^{0}\right)\right]\left\{\left[\frac{F\left(K^{+}\right)\left(1+e^{+}\right)+(1-\ddot{\mathrm{a}}) K^{+}}{1+r^{*}}\right]-\left[K^{+}-(1-\ddot{\mathrm{a}}) K_{0}\right]\right\} .
\end{array}
$$

The first curly-bracketed term on the right-hand side of (6) represents the expected value of the firm conditional on its being equity-financed, which will occur with probability $\mathrm{O}\left(\varepsilon_{0}\right)$. Similarly, the second curly-bracketed term represents the expected value of the firm conditional on its making no new investment, which will occur with probability $\ddot{O}\left(\varepsilon^{0}\right)-\ddot{O}\left(\varepsilon_{0}\right)$. The third curlybracketed term represents the expected value of the firm conditional on its being debt-financed, which will occur with probability $1-\ddot{O}\left(\varepsilon^{0}\right)$.

Maximization of (6) with respect to $\mathrm{K}^{-}$and $\mathrm{K}^{+}$yields the marginal capital productivity conditions:

$$
\mathrm{F}^{\prime}\left(\mathrm{K}^{-}\right)\left(1+\mathrm{e}^{-}\right)=\mathrm{r}^{*}+\ddot{a},
$$

and

$$
\mathrm{F}^{\prime}\left(\mathrm{K}^{+}\right)\left(1+\mathrm{e}^{+}\right)=\mathrm{r}^{*}+\ddot{a}
$$

The expected marginal product of capital, either under equity finance or debt finance, must equal the cost of capital $\left(r^{*}+\ddot{a}\right)$. Note that since the mean productivity factor for the high- $\varepsilon$ firms (i.e., $\mathrm{e}^{+}$) is higher than the mean productivity factor for the low- $\varepsilon$ firms (i.e., $\mathrm{e}^{-}$), $\mathrm{K}^{+}$is bigger than $\mathrm{K}^{-}$. In other words, the high-productivity firms invest more than the low-productivity firms while the medium-productivity firms do not invest at all. This is depicted in Figure 2 as the market solution (in contrast to the efficient solution to be discussed in section IV below). 


\section{II.F The rest of the model}

We denote the utility function of the representative household by

$$
\mathrm{U}\left(\mathrm{C}_{1}, \mathrm{C}_{2}\right) \text {, }
$$

where $C_{t}$ is her consumption in period $t=1,2$. The consumer chooses her first and second period consumption (along with the residual saving) by maximizing her utility subject to her lifetime budget constraint. This maximization delivers the standard intertemporal condition:

$$
\mathrm{U}_{1} / \mathrm{U}_{2}=1+\mathrm{r}^{*} \text {. }
$$

Domestic investment is financed by domestic savings and capital imports. The intertemporal resource constraint is given by:

$$
\begin{aligned}
\mathrm{C}_{1}+\mathrm{C}_{2} /\left(1+\mathrm{r}^{*}\right)+\mathrm{NO}\left(\varepsilon_{0}\right)\left[\mathrm{K}^{-}-(1-\ddot{\mathrm{a}}) \mathrm{K}_{0}\right]+\mathrm{N}\left[1-\ddot{\mathrm{O}}\left(\varepsilon^{0}\right)\right]\left[\mathrm{K}^{+}-(1-\ddot{\mathrm{a}}) \mathrm{K}_{0}\right] \\
=\mathrm{NF}\left(\mathrm{K}_{0}\right)+\mathrm{NO}\left(\varepsilon_{0}\right)\left[\mathrm{F}\left(\mathrm{K}^{-}\right)\left(1+\mathrm{e}^{-}\right)+(1-\ddot{\mathrm{a}}) \mathrm{K}^{-}\right] /\left(1+\mathrm{r}^{*}\right) \\
+\mathrm{N}\left[\ddot{\mathrm{O}}\left(\varepsilon^{0}\right)-\ddot{\mathrm{O}}\left(\varepsilon_{0}\right)\right]\left\{\mathrm{F}\left[(1-\ddot{\mathrm{a}}) \mathrm{K}_{0}\right]\left(1+\mathrm{e}^{0}\right)+(1-\ddot{\mathrm{a}})^{2} \mathrm{~K}_{0}\right\} /\left(1+\mathrm{r}^{*}\right) \\
+\mathrm{N}\left[1-\ddot{\mathrm{O}}\left(\varepsilon^{0}\right)\right]\left[\mathrm{F}\left(\mathrm{K}^{+}\right)\left(1+\mathrm{e}^{+}\right)+(1-\ddot{\mathrm{a}}) \mathrm{K}^{+}\right] /\left(1+\mathrm{r}^{*}\right) .
\end{aligned}
$$

It states that the present value of consumption and investment (i.e., the uses of funds) cannot exceed the present value of output and the undepreciated stocks of capital at the end of the production process (i.e., the sources of funds). Note also that, in period one, there is an amount of output $\mathrm{NF}\left(\mathrm{K}_{0}\right)$ whose production began one period earlier. The capital inflows, denoted FI (for foreign investment) simply equal the excess of domestic investment over domestic saving, i.e.,

$$
\mathrm{FI}=\left\{\mathrm{NÖ}\left(\varepsilon_{0}\right)\left[\mathrm{K}^{-}-(1-\ddot{\mathrm{a}}) \mathrm{K}_{0}\right]+\mathrm{N}\left[1-\ddot{\mathrm{O}}\left(\varepsilon^{0}\right)\right]\left[\mathrm{K}^{+}-(1-\ddot{\mathrm{a}}) \mathrm{K}_{0}\right]\right\}-\left[\mathrm{NF}\left(\mathrm{K}_{0}\right)-\mathrm{C}_{1}\right] .
$$

On the right hand side of this equation, the first term relative to the second term indicates the magnitude of international equity flows relative to international debt flows. If the "lemons" problem are severe in the domestic equity market, we can expect that the relative magnitude of international equity flows to be small. 


\section{Constrained Efficiency}

An intrinsic feature of this economy is that the investment rule cannot be fine-tuned to be completely state-contingent. The desired stocks of capital must be determined ex ante before $\varepsilon$ is revealed and, once it is revealed, the managers can only choose whether to carry out the predetermined debt-financed level of investment, or equity-financed level of investment, or not to invest at all. In other words, a refined and continuous state-dependent function $K(\varepsilon)$ for the desired stock of capital is ruled out. For a sensible evaluation of this market solution, we therfore look for a benchmark efficiency concept that respects this quasi-institutional constraint.

This constraint boils down to dividing the firms into at most three categories: lowproductivity investing firms, medium-productivity non-investing firms, and high-productivity investing firms. We first ask whether the market distribution of the firms into these three categories is efficient. In particular, one may ask whether the middle category should vanish, so that all firms should invest. We then ask whether the investment levels for the firms in the two investing categories are efficient. Specifically, we ask whether $\varepsilon_{0}, \varepsilon^{0}, \mathrm{~K}^{-}, \mathrm{K}^{+}$are efficient.

Formally, the efficient allocation is determined by choosing $\left\{\mathrm{C}_{1}, \mathrm{C}_{2}, \varepsilon_{0}, \varepsilon^{0}, \mathrm{~K}^{-}, \mathrm{K}^{+}\right\}$to maximize the utility function of the representative household (9) subject to the economy-wide resource constraint (11). The first order conditions (see the Appendix) are given by:

$$
\begin{gathered}
\mathrm{U}_{1} / \mathrm{U}_{2}=1+\mathrm{r}^{*}, \\
\mathrm{~F}^{\prime}\left(\mathrm{K}^{-}\right)\left(1+\mathrm{e}^{-}\right)=\mathrm{r}^{*}+\ddot{\mathrm{a}}, \\
\mathrm{F}^{\prime}\left(\mathrm{K}^{+}\right)\left(1+\mathrm{e}^{+}\right)=\mathrm{r}^{*}+\ddot{\mathrm{a}}, \\
-\left[\mathrm{K}^{-}-(1-\ddot{\mathrm{a}}) \mathrm{K}_{0}\right]+\left[\mathrm{F}\left(\mathrm{K}^{-}\right)\left(1+\varepsilon_{0}\right)+(1-\ddot{\mathrm{a}}) \mathrm{K}^{-}\right] /\left(1+\mathrm{r}^{*}\right) \\
=\left\{\mathrm{F}\left[(1-\ddot{\mathrm{a}}) \mathrm{K}_{0}\right]\left(1+\varepsilon_{0}\right)+(1-\ddot{\mathrm{a}})^{2} \mathrm{~K}_{0}\right\} /\left(1+\mathrm{r}^{*}\right), \\
-\left[\mathrm{K}^{+}-(1-\ddot{\mathrm{a}}) \mathrm{K}_{0}\right]+\left[\mathrm{F}\left(\mathrm{K}^{+}\right)\left(1+\varepsilon^{0}\right)+(1-\ddot{\mathrm{a}}) \mathrm{K}^{+}\right] /\left(1+\mathrm{r}^{*}\right) \\
=\left\{\mathrm{F}\left[(1-\ddot{\mathrm{a}}) \mathrm{K}_{0}\right]\left(1+\varepsilon^{0}\right)+(1-\ddot{\mathrm{a}})^{2} \mathrm{~K}_{0}\right\} /\left(1+\mathrm{r}^{*}\right),
\end{gathered}
$$


Since $\mathrm{e}^{+}>\mathrm{e}^{-}$, (7a) and (8a) imply that $\mathrm{K}^{-}$is smaller than $\mathrm{K}^{+}$, i.e., the low- $\varepsilon$ firms should invest less than the high- $\varepsilon$ firms. We can also show that the set of non-investing firms is not empty, i.e. $\varepsilon_{0}<\varepsilon^{0}$. To see this, suppose to the contrary that $\varepsilon_{0}=\varepsilon^{0}$. (Note that the possibility of $\varepsilon_{0}>\varepsilon^{0}$ is redundant because of the symmetry between $\left(\mathrm{K}^{-}, \varepsilon_{0}\right)$ and $\left(\mathrm{K}^{+}, \varepsilon^{0}\right)$.) It then follows from (2a) and (3a) that $\mathrm{K}^{-}$must equal $\mathrm{K}^{+}$, which contradicts (7a) and (7b), given $\mathrm{e}^{+}>\mathrm{e}^{-}$.

\section{Market Failure and Corrective Policy}

Is the market allocation constrained efficient the way we have defined it above? Recall that the market allocation is characterized by conditions (2), (3), (7), (8), and (10) and the constrained efficient allocation by (2a), (3a), (7a), (8a), and (10a). Of course, the two allocations satisfy also the intertemporal resource constraint (11).

Observe that conditions (3a), (7a), (8a), and (10a) are identical to (3), (7), (8), and (10) respectively. The intertemporal market allocation of consumption follows the constrained efficiency rule. Somewhat strikingly, the debt market is efficient, both in its width (as indicated by $\left.\varepsilon^{0}\right)$ and in the level of investment $\left(\mathrm{K}^{+}-(1-\ddot{a}) \mathrm{K}_{0}\right)$ carried out by each debt-financed firm.

The equity market fails, however, both in its width (as indicated by $\varepsilon_{0}$ ) and the level of investment $\left(\mathrm{K}^{-}-(1-\ddot{\mathrm{a}}) \mathrm{K}_{0}\right)$ carried out by each equity-financed firm. We can show that the equity market is too narrow, and the capital investment it finances too low; see Figure 2. Thus, the aggregate stock of capital under the market allocation is less than efficient. To prove this, suppose that the cutoff level of $\varepsilon$ in the equity market $\left(\varepsilon_{0}\right)$ is at the efficient level. Then (7) and (7a) imply that the capital investment $\left(\mathrm{K}^{-}\right)$is also efficient. Now, consider the marginal firm which realizes a value of $\varepsilon$ equal to $\varepsilon_{0}$. Its market value is given by the left-hand side of (2a) with $\varepsilon_{0}$ replaced by $\mathrm{e}^{-}$. Since $\mathrm{e}^{-}<\varepsilon_{0}$, its market value (computed in terms of the average productivity of the firms in the equity market) must fall short of its alternative no-investment value as known 
to this marginal firm, which actually observes that its $\varepsilon$ is equal to $\varepsilon_{0}$. This firm will thus drop out of the market, and the equity market will shrink in size. As a result, the equity market $\varepsilon_{0}$ will fall short of the efficient $\varepsilon_{0}$. Furthermore, the equity market $\mathrm{K}^{-}$will be below the efficient $\mathrm{K}^{-}$because the equity market $\mathrm{e}^{-}$is below the efficient $\mathrm{e}^{-}$(cf. (7) and (7a)). The reason for this market failure lies in the fact that the marginal firm is unable to extract its true market value as known to her and has to settle for the average market value of all firms in the market. That is, the decision of the marginal firm whether to equity-finance its investment is dictated by the comparison between the average value of investment (based on the average $\varepsilon$, which is $\mathrm{e}^{-}$) and the marginal value of not investing (based on $\varepsilon_{0}$ ). On the other hand, the metaphorical planner, who determines the constrained efficient allocation, weighs the marginal value of equity-financed investment (at $\left.\varepsilon_{0}\right)$ against the marginal value of no investment (also at $\varepsilon_{0}$ ).

The prescription for corrective policy is straightforward. What is needed is simply to correct the equity market cutoff level of $\varepsilon$ (i.e., $\varepsilon_{0}$ ). As can be seen from (7) and (7a), once the cutoff $\varepsilon_{0}$ and hence $\mathrm{e}^{-}$are set at their efficient levels, the stock of capital $\left(\mathrm{K}^{-}\right)$will adjust to the efficient level as well. Comparing (2) and (2a), we can also see that the market $\varepsilon_{0}$ will coincide with the efficient $\varepsilon_{0}$ if a lump-sum subsidy is granted to the equity-financed firms so as to equate for the marginal firm its market value (inclusive of the subsidy) to its true value as observed by its manager. That is, the subsidy $(\mathrm{S})$ is set such that $\mathrm{S}+\mathrm{F}\left(\mathrm{K}^{-}\right)\left(1+\mathrm{e}^{-}\right)=\mathrm{F}\left(\mathrm{K}^{-}\right)\left(1+\varepsilon_{0}\right)$, which yields

$$
\mathrm{S}=\mathrm{F}\left(\mathrm{K}^{-}\right)\left(\varepsilon_{0}-\mathrm{e}^{-}\right)>0
$$

Note that this subsidy must be a lump sum, affecting only the decision whether to invest through equity finance or not to invest (i.e., to be in the equity market or to drop out of it) without interfering with the marginal productivity condition (7a) of how much to invest. ${ }^{7}$ This

\footnotetext{
${ }^{7}$ Observe, for instance, from equations (2) and (2a) that while a marginal subsidy of $\mathrm{s}=\left(\varepsilon_{0}-\mathrm{e}^{-}\right) /\left(1+\mathrm{e}^{-}\right)$to each firm that equity-finances its investment will correct the distortions at the $\varepsilon_{0}$-margin, it will introduce an unnecessary distortion at the $\mathrm{K}^{-}$-margin, with $(7)$ rewritten as $(1+\mathrm{s}) \mathrm{F}^{\prime}\left(\mathrm{K}^{-}\right)\left(1+\mathrm{e}^{-}\right)=\mathrm{r}^{*}+\ddot{a}$.
} 
somewhat unconventional policy of a lump-sum subsidy that is conditional on joining the equity market suffices to restore constrained efficiency for the entire economy.

\section{Conclusion}

This paper considers the financing of investment in the presence of asymmetric information between the "insiders" and the "outsiders" of the firms in a small open economy. It establishes a well-defined capital structure for the economy as a whole with the following features: lowproductivity firms rely on the equity market to finance investment at a relatively low level; medium-productivity firms do not invest at all; and high-productivity firms rely on the debt market to finance investment at a relatively high level. It is shown that the debt market is efficient, with respect to both its scope and the amount of investment that each firm makes. However, the equity market fails: its scope is too narrow and the investment each firm makes is too little. A corrective policy requires just one policy instrument which is rather unconventional: lump-sum subsidies to those firms that choose to equity-finance their investment (i.e., equity-marketcontingent grants).

Our theoretical framework and the associated results suggest two empirical implications. First, if there exist systematic changes in the distribution of high- and low-productivity firms during the business cycle, then the debt-equity structure in the economy will vary over the cycles in a systematic manner. In particular, if the distribution of firms tilts towards relatively high productivity firms because of their cleansing effect during recessions, then the debt-equity ratio will rise. Similarly, the debt-equity ratio will fall during economic booms because a group of new (low-productivity) firms will enter. Second, during the process of capital market development, as rules of disclosure and prudential regulations get increasingly incorporated into the workings of these markets, one can conjecture that the "lemons" problem in the equity market will become 
less serious. As a result, the debt-equity ratio is likely to fall. Indeed, the comparison in the composition of capital flows between low- and middle-income countries reveal a relatively larger inflow of equity (see Figure 3).

[insert Figure 3 about here] 


\section{References}

Akerlof, George, "The market for 'lemons': Qualitative uncertainty and the market mechanism," Quarterly Journal of Economics 89 (1970), 488-500.

Chen, Zhaohui, and Mohsin S. Khan, "Patterns of Capital Flows to Emerging Markets: A Theoretical Perspective,” IMF Working Paper WP/97/13, 1997.

Eaton, Jonathan, and Mark Gersovitz, "Country Risk and the Organization of International Capital Transfer," in Guillermo A. Calvo, et al. (Eds.), Debt, Stabilization, and Development: Essays in Memory of Carlos Diaz-Alejandro, Basil Blackwell (New York, NY), 1989.

Gertler, Mark, and Kenneth Rogoff, "North-South Lending and Endogenous Capital Market Inefficiencies," Journal of Monetary Economics 26 (1990), 245-266.

Gordon, Roger H., and A. Lans Bovenberg, "Why is capital so immobile internationally?: Possible explanations and implications for capital income taxation," American Economic Review 86 (1996), 1057-75.

Lane, Philip R., "North-South Lending under Moral Hazard and Repudiation Risk," Review of International Economics (1998), forthcoming.

Myers, Stewart C., and Nicholas S. Majluf, "Corporate Financing and Investment Decisions When Firms Have Information that Investors Do Not Have," Journal of Financial Economics 13 (1984), 187-221.

Razin, Assaf, Efraim Sadka, and Chi-Wa Yuen, "Channelling Domestic Savings into Productive Investment: The Essential Role of Foreign Direct Investment," mimeo, International Monetary Fund, 1998a.

, "A pecking order of capital inflows and international tax principles," Journal of International Economics 44 (1998b): 45-68.

Stiglitz, Joseph E., and Andrew Weiss, "Credit rationing in markets with imperfect information," American Economic Review 71 (1981), 393-410.

Tesar, Linda L., and Ingrid M. Werner, "U.S. Equity Investment in Emerging Stock Markets," World Bank Economic Review 9 (1995), 109-29. 


\section{Appendix}

In this appendix, we derive the first order conditions for constrained efficiency (i.e., equations (2a), (3a), (7a), (8a), and (10a) in the text). For this purpose, we first express the derivatives of $\mathrm{e}^{-}\left(\varepsilon_{0}\right)$ from equation (1), $\mathrm{e}^{+}\left(\varepsilon^{0}\right)$ from equation (4), and $\mathrm{e}^{0}\left(\varepsilon_{0}, \varepsilon^{0}\right)$ from equation (5), with respect to their corresponding arguments as follows:

$$
\begin{gathered}
\frac{d e^{-}\left(\varepsilon_{0}\right)}{d \varepsilon_{0}}=\left(\frac{\ddot{\mathrm{O}}^{\prime}\left(\varepsilon_{0}\right)}{\ddot{\mathrm{O}}\left(\varepsilon_{0}\right)}\right)\left(\varepsilon_{0}-e^{-}\right)>0 . \\
\frac{d e^{+}\left(\varepsilon^{0}\right)}{d \varepsilon^{0}}=\left(\frac{\ddot{\mathrm{O}}^{\prime}\left(\varepsilon^{0}\right)}{\left.\ddot{\mathrm{O}}^{0} \varepsilon^{0}\right)}\right)\left(e^{+}-\varepsilon^{0}\right)>0 . \\
\frac{\partial e^{0}\left(\varepsilon_{0}, \varepsilon^{0}\right)}{\partial \varepsilon_{0}}=\left(\frac{\ddot{\mathrm{O}}^{\prime}\left(\varepsilon_{0}\right)}{\left.\ddot{\mathrm{O}}_{\left(\varepsilon^{0}\right)-\ddot{O}\left(\varepsilon_{0}\right)}\right)}\right)\left(e^{0}-\varepsilon_{0}\right)>0 . \\
\frac{\partial e^{0}\left(\varepsilon_{0}, \varepsilon^{0}\right)}{\partial \varepsilon^{0}}=\left(\frac{\ddot{\mathrm{O}}^{\prime}\left(\varepsilon_{0}\right)}{\ddot{\mathrm{O}}\left(\varepsilon^{0}\right)-\ddot{O}_{(}\left(\varepsilon_{0}\right)}\right)\left(\varepsilon^{0}-e^{0}\right)>0 .
\end{gathered}
$$

The metaphorical planner's constrained efficiency problem is to maximize the utility of the representative household (9) subject to the economy-wide intertemporal resource constraint (11) by choice of $\left\{\mathrm{C}_{1}, \mathrm{C}_{2}, \varepsilon_{0}, \varepsilon^{0}, \mathrm{~K}^{-}, \mathrm{K}^{+}\right\}$. The first order conditions for $\mathrm{C}_{1}$ and $\mathrm{C}_{2}$ yield (10a), while those for $\mathrm{K}^{-}$and $\mathrm{K}^{+}$yield (7a) and (8a) respectively, in the text. The first order conditions for $\varepsilon_{0}$ and $\varepsilon^{0}$ are given by the following two equations:

$$
\begin{gathered}
\ddot{\mathrm{O}}^{\prime}\left(\varepsilon_{0}\right)\left[F\left(K^{-}\right)\left(1+e^{-}\right)+(1-\ddot{\mathrm{a}}) K^{-}\right]+\ddot{\mathrm{O}}\left(\varepsilon_{0}\right) F\left(K^{-}\right)\left(d e^{-} / d \varepsilon_{0}\right) \\
\left.-\ddot{\mathrm{O}}^{\prime}\left(\varepsilon_{0}\right)\left\{F\left[(1-\ddot{\mathrm{a}}) K_{0}\right)\right]\left(1+e^{0}\right)+(1-\ddot{\mathrm{a}})^{2} K_{0}\right\}+\left[\ddot{\mathrm{O}}\left(\varepsilon^{0}\right)-\ddot{\mathrm{O}}\left(\varepsilon_{0}\right)\right] F\left[(1-\ddot{\mathrm{a}}) K_{0}\right]\left(\partial e^{0} / \partial \varepsilon_{0}\right)(\mathrm{A} .5) \\
=\ddot{\mathrm{O}}^{\prime}\left(\varepsilon_{0}\right)\left[K^{-}-(1-\ddot{\mathrm{a}}) K_{0}\right]\left(1+r^{*}\right) . \\
\left.-\ddot{\mathrm{O}}^{\prime}\left(\varepsilon^{0}\right)\left\{F\left[(1-\ddot{\mathrm{a}}) K_{0}\right)\right]\left(1+e^{0}\right)+(1-\ddot{\mathrm{a}})^{2} K_{0}\right\}-\left[\ddot{\mathrm{O}}\left(\varepsilon^{0}\right)-\ddot{\mathrm{O}}\left(\varepsilon_{0}\right)\right] F\left[(1-\ddot{\mathrm{a}}) K_{0}\right]\left(\partial e^{0} / \partial \varepsilon^{0}\right)(\mathrm{A} .6) \\
=\ddot{\mathrm{O}}^{\prime}\left(\varepsilon^{0}\right)\left[K^{+}-(1-\ddot{\mathrm{a}}) K_{0}\right]\left(1+r^{*}\right) .
\end{gathered}
$$

Substituting (A.1)| (A.4) into (A.5) and (A.6) yields (2a) and (3a) respectively. 
Figure 1. Composition of Private Capital Flows

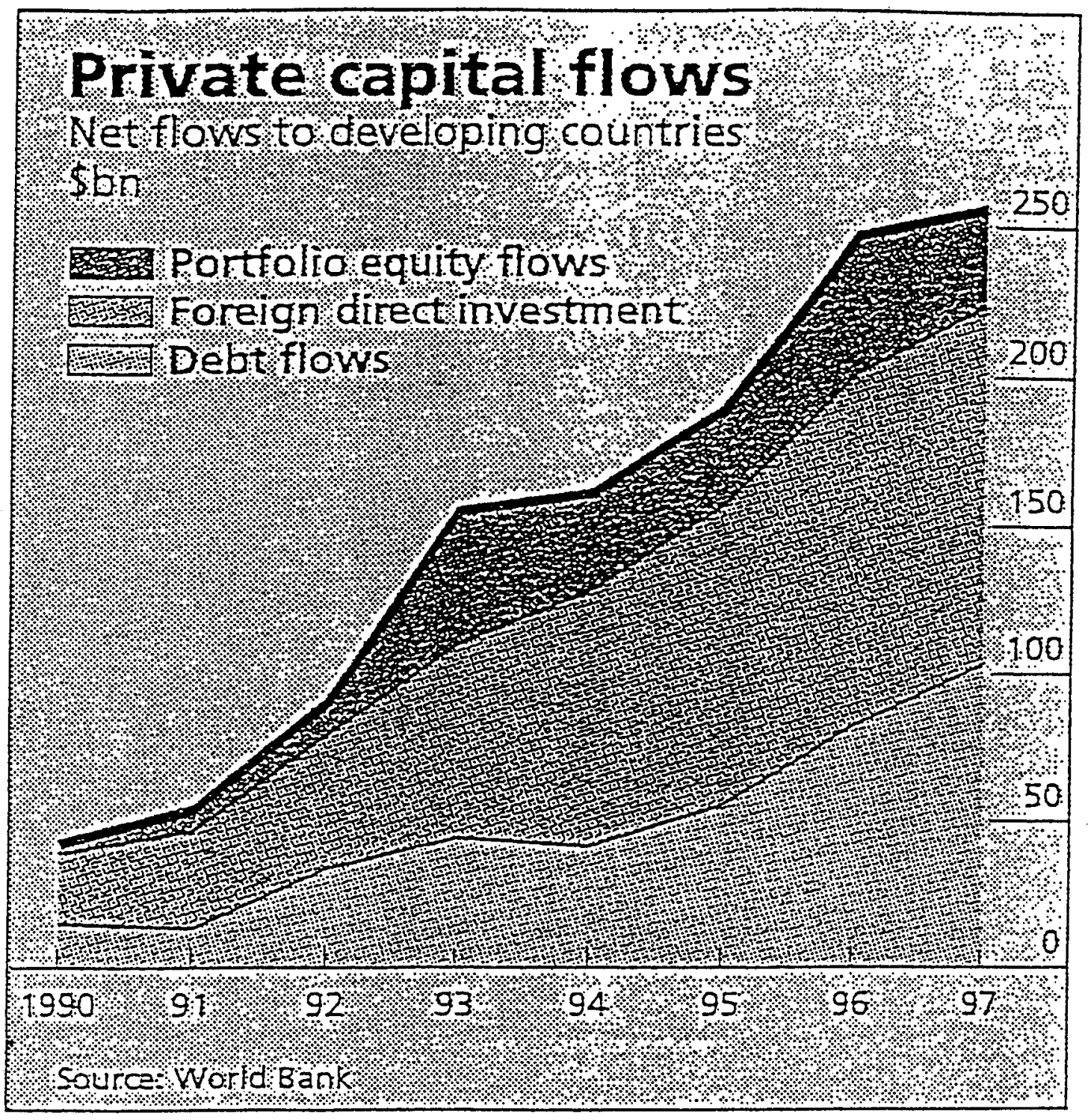




\section{Figure 2}

Productivity and the Stock of Capital: Market vs. Efficient Solution

Stock of capital (K)

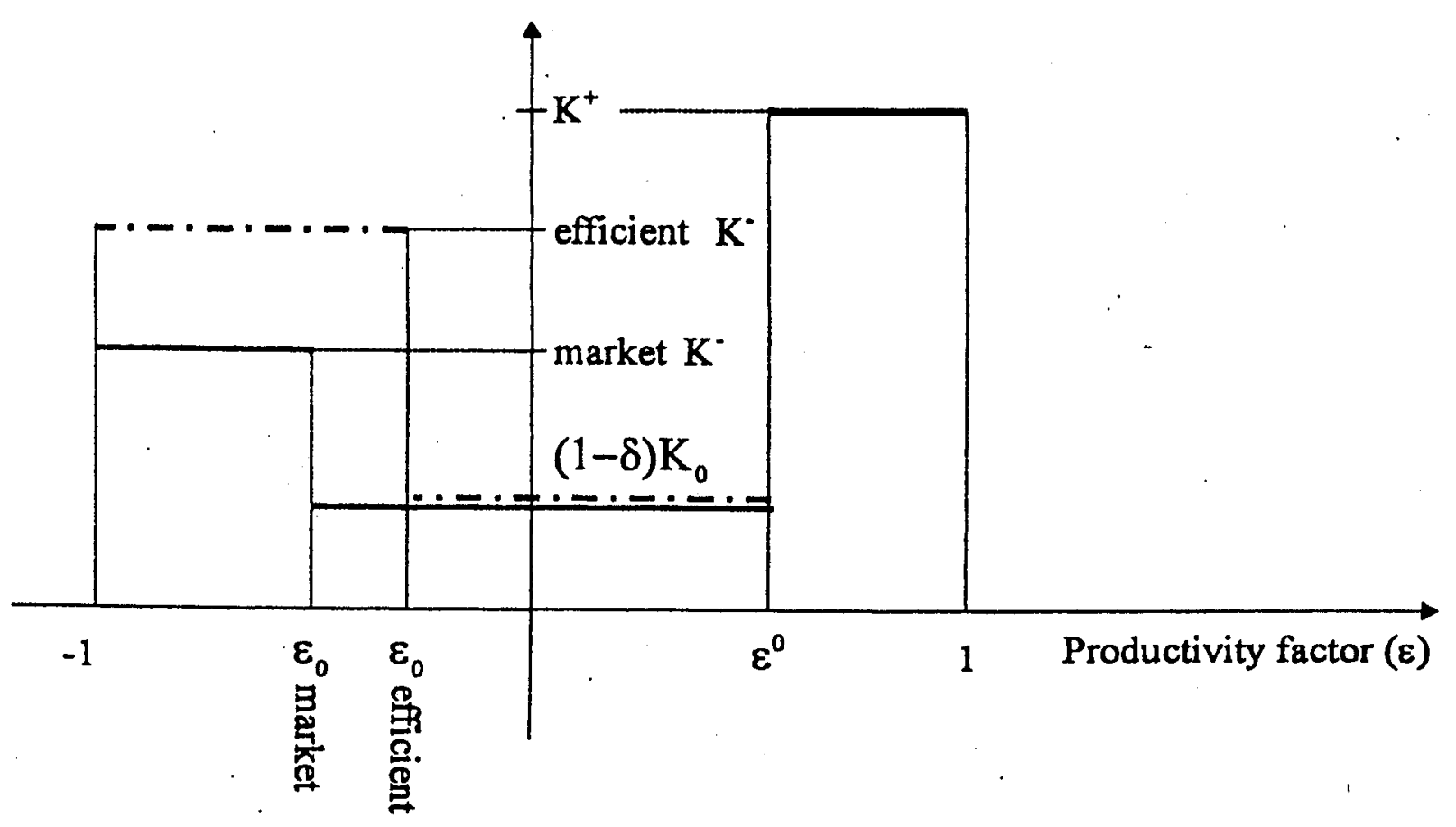

N.B. Note that $\varepsilon_{0}$ need not be negative and $\varepsilon^{0}$ need not be positive. The values of $K^{+}$and $\varepsilon^{0}$ are the same under the two solutions. 
Figure 3. Composition of Capital Flows, 1980-95* (in percent)

(a) Low Income Countries

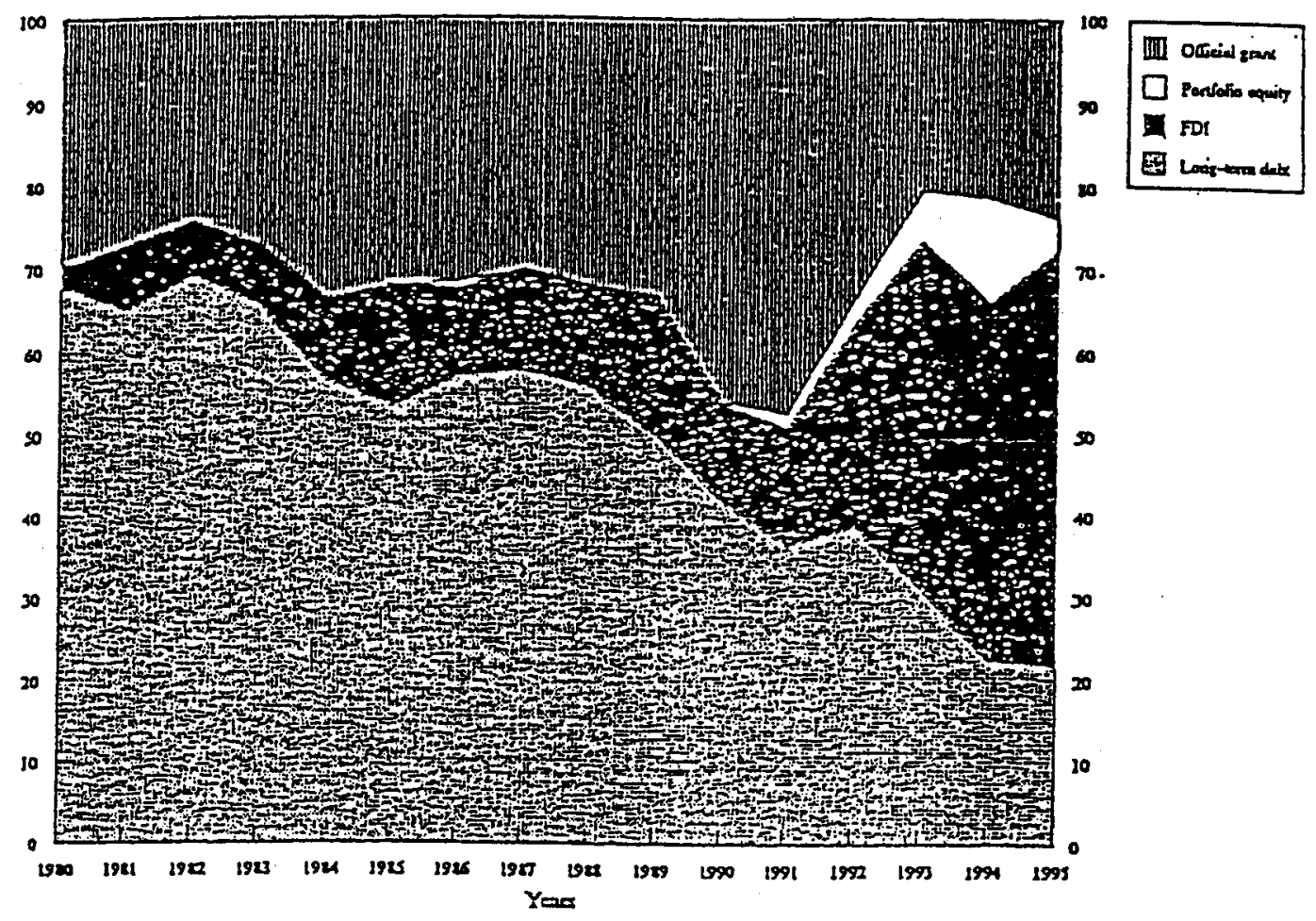

(b) Medium Income Countries

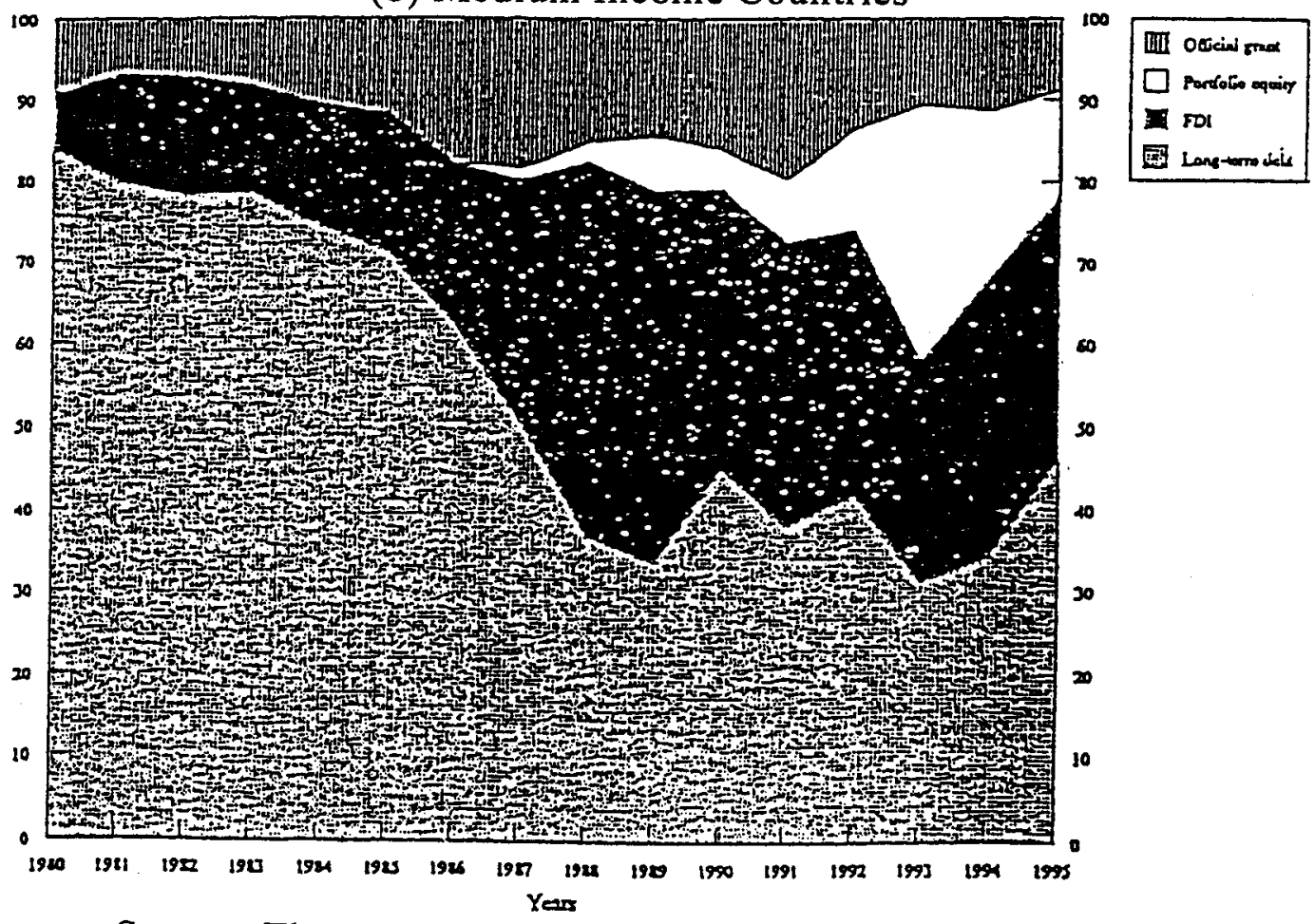

Source: The World Bank, World Debt Tables.

*1995 figures are estimates

Reproduced from Chen and Khan (1997) 